\title{
Driver feedback mobile app
}

\author{
Francesc Soriguera Martí \\ Associate Professor, CENIT - UPC-BarcelonaTech, Spain \\ Enric Miralles Miquel \\ Researcher, Barcelona School of Civil Engineering, UPC-BarcelonaTech, Spain
}

\begin{abstract}
This paper faces the human factor in driving and its consequences for road safety. It presents the concepts behind the development of a smartphone app capable of evaluating drivers' performance. The app provides feedback to the driver in terms of a grade (between 0 and 10) depending on the aggressiveness and risks taken while driving. These are computed from the cumulative probability distribution function of the jerks (i.e. the time derivative of acceleration), which are measured using the smartphones' accelerometer. Different driving contexts (e.g. urban, freeway, congestion, etc.) are identified applying cluster analysis to the measurements, and treated independently. Using regression analysis, the aggressiveness indicator is related to the drivers' safety records and to the probability of having an accident, through the standard DBQ - Driving Behavior Questionnaire. Results from a very limited pilot test show a strong correlation between the $99^{\text {th }}$ percentile of the jerk measurements and the DBQ results. A linear model is fitted. This allows quantifying the safe driving behavior only from smartphone measurements. Finally, this indicator is translated into a normalized grade and feedback to the driver. This feedback will challenge the driver to train and to improve his performance. The phone will be blocked while driving and will incorporate mechanisms to prevent bad practices, like competition in aggressive driving. The app is intended to contribute to the improvement of road safety, one of the major public health problems, by tackling the human factor which is the trigger of the vast majority of traffic accidents. Making explicit and quantifying risky behaviors is the first step towards a safer driving.
\end{abstract}

Keywords: Road safety, driving aggressiveness, driver feedback, smartphone app, driving performance.

\section{INTRODUCTION AND OBJECTIVES}

Although declining in the recent past, the number of deaths as a result of road accidents is still one of the major public health problems in developed countries. Besides, accident rates for motorcycles are not following the general trends of road safety progress [CARE (2011)]. Moreover motorcycle fleet is experiencing a huge increase $(+22 \%$ over the period 20022007 as reported by the Association of European Motorcycle Manufacturers - ACEM). This situation urges to an increased effort for improving road safety with special consideration of motorcyclists. 
Research efforts on road safety have been concentrated on infrastructures and vehicles. There is much less research conducted worldwide in relation to the human factor. In spite of this, in over $90 \%$ of the cases the human behavior is the trigger of traffic accidents [SCT, 2014]. Scientific literature aimed to understand drivers' behavior is scarce, and even more if one focuses on motorbike riders [Chesham et al. (1993); 2BESAFE (2011)]. The reason for this gap in the literature lies in the difficulties encountered in the scientific analysis of driver behavior. Challenges are technical, but also economical, due to the required instrumentation of a large number of vehicles in order to enable data collection on-road.

Understanding drivers' behavior is essential for the improvement of road safety. The design of relevant countermeasures for safety improvement, or the definition of the training curriculum in order to obtain the driving permit, must be based upon scientific evidences on driver behavior. Also external and objective feedback is needed by the driver in order to improve his driving skills. In fact, the lack of feedback to the driver is one of the main problems regarding the driving performance. There are studies [Walton and Barthurst (1998)] showing that the vast majority of drivers consider their own driving skills better than average, regardless of their driving records. This is what psychologists call "optimistic bias", also suffered by the investors in the stock market. Even the circumstances when the driver is about to have an accident are perceived as proves of the ability at the steering wheel. This driving narcissism encourages an aggressive behavior [Vanderbilt, 2009].

This does not mean that drivers are unaware of the risks of driving. However, an overestimation of the social risks and an underestimation of individual risks occur. This means, for example, that while every individual driver is in favor of banning the use of mobile phones while driving, everyone uses them (see [NHTSA (2007)] for an interesting analysis of this phenomenon in relation to safety seat belts). It is common the idea that "it is the behavior of others that should be controlled, not mine". A similar phenomenon occurs in relation to the use of public transport.

Many drivers have driving habits with high accident probability without being aware of it, at all. One could be a bad driver for years without ever knowing it. Furthermore, because a person who cannot write is not able to correctly judge a text, a bad driver will not be in the best position to assess their own risk while driving [Vanderbilt, 2009]. External feedback is needed. Currently, the feedback available to drivers is limited to the traffic tickets, the withdrawal of points in the driving license, and to the accidents suffered, with the aggravating fact that, very often, drivers do not consider this feedback as objective. For instance, the driver may attribute traffic tickets to the bad character of the police officer "that needs to fine in order to meet his quota" and accidents to "external conditions" or "pure bad luck." Since most trips end without tickets or accidents, the idea that every day we are better drivers is reinforced.

This occurs because the feedback is limited to elements close to the apex of Heinrich's pyramid, composed of serious but rare events [Manuele, 2003]. Heinrich's pyramid is 
nothing more than a classification based on accident frequency and severity (see Figure 1). Heinrich proved that the key element to avoid the serious and less frequent events in the upper zone lies in the reducing the vast number of small events in the pyramid's base. This view is diametrically opposed to the concept of "accident" which implicitly covers all the negligent behaviors. The reality is that road accidents (i.e. the apex of the pyramid) do not happen by unpredictable laws, but by the fact that drivers routinely drive in a way (i.e. base of the pyramid) so that accidents become inevitable.

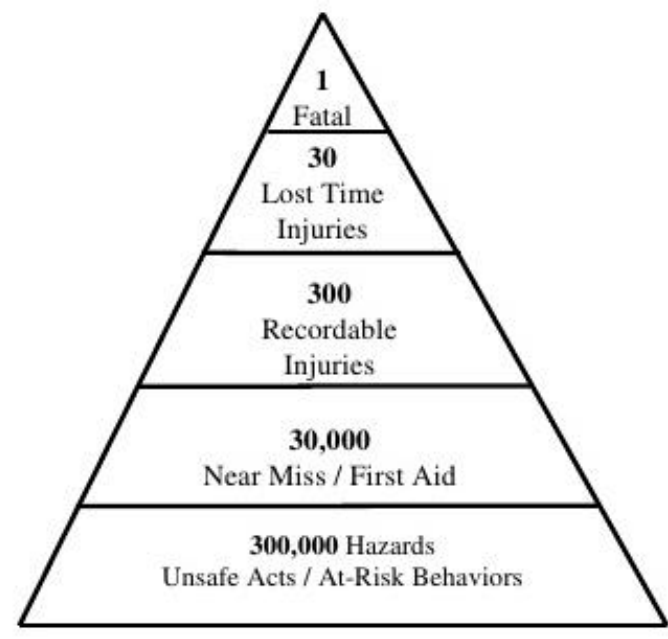

\section{Fig. 1 - An illustration of Heinrich's theory: The safety pyramid}

One of the first and only initiatives to increase the driver feedback was led by commercial vehicle fleets with slogans such as "Tell me how I drive" painted in the vehicle along with a phone number. However, in these examples the feedback comes late, it is of dubious quality, and it is biased towards the negative elements. Other tools to provide feedback to the driver and scientific literature on the topic are both extremely limited.

In light of this background, the approach proposed in this paper consists on the development of a tool capable of monitoring the driver performance and to provide him with feedback. The conceptual framework behind this approach lies in the external "recording" of the driving activity in order to show to the driver things he is not aware of. Similarly as it is done in the learning of multiple sports, like swimming, tennis, golf... The obtained "driving grade" will also create a reputation system (indicator in relation to the mean) that human nature tends to maximize. Moreover, by simply participating in an "experiment" the driver modifies his behavior trying to beat the system. This is known as the Hawthorne effect [EMS Insider (2004)]. Knowing it or not, drivers will drive safer.

The tool will describe the driver performance, in terms of safe driving, with a quantitative indicator (i.e. a grade) and represent him in relation to the average driver (e.g. achieved percentile of the distribution of grades). A relationship between the obtained grade and the historical records of the driver (i.e. accidents or near accidents, traffic tickets, etc.) will be 
established in order to empirically relate the safety indicator with the risks faced and with the probability of an accident. The results of the measurements and model, are translated into an easily understandable grade between 0 and 10 , so that the final output will be a clear and objective feedback from which the driver can improve his safety on the road.

The tool (i.e. the instrumentation of the vehicle) should be minimal, economical, and adaptable to both, cars and motorbikes. Previous research on naturalistic driving studies have been undertaken with ad-hoc fully instrumented vehicles (see [SHRP2 (2011)] for a literature review), which implied very limited data samples. Here, the monitoring of driver performance will use their own smartphones. These fulfill all the technical requirements, and are ready available, waiting in the vast majority of travelling vehicles. The monitoring tool (i.e. the smartphone app) is designed so that it can be used by motorcyclists, a particularly vulnerable group experiencing worsening accident trends.

The rest of the paper is organized as follows. In Section 2 the methodology used to compute the grade is presented. This includes the identification of the driving context, the computation of the aggressiveness indicator from jerk measurements, and its relation to safe driving through the DBQ - Driving Behavior Questionnaire. Next, in Section 3 a very limited pilot test, with only 7 drivers, is presented. This is only intended to illustrate the application of the methodology. A more extensive test would be needed in order to derive robust results. Finally, in Section 4 some conclusions and directions for further research are outlined.

\section{METHODOLOGY}

Smartphones are used as the in-vehicle surveillance instrumentation. Its widespread use and availability makes them very suitable measuring equipment. Currently, most smartphones (e.g. iPhone and Android platforms, see Figure 2) can register position and speed (with GPS accuracy). Also, the three component acceleration vector (from the internal accelerometer), rotation angles (pitch, roll and yaw) and rotational speed (from the internal gyroscope) can be measured. It is possible to select the time averaging interval, reaching a maximum discretization of $0.02 \mathrm{~s}(50 \mathrm{~Hz})$. These must be the input data.

The methodology used in order to compute the safe driving indicator from the raw measurements, is divided into three steps. First, the driving context is established. The dynamics of motion (i.e. speeds, acceleration and jerks) and their impacts on traffic safety are different depending on the driving context (e.g. urban vs freeway driving). Second, the indicator needs to be computed from the smartphone raw measurements. And third, this indicator needs to be related with the safe driving behavior. This third step is accomplished by relating the quantitative value of the indicator with the qualitative drivers' behavior and their historical records in terms of safe driving. The Driver Behavior Questionnaire (DBQ) widely used in the study of drivers' psychology [Parker et al. 1995; Zapf and Reason 1994] is used to this end. 

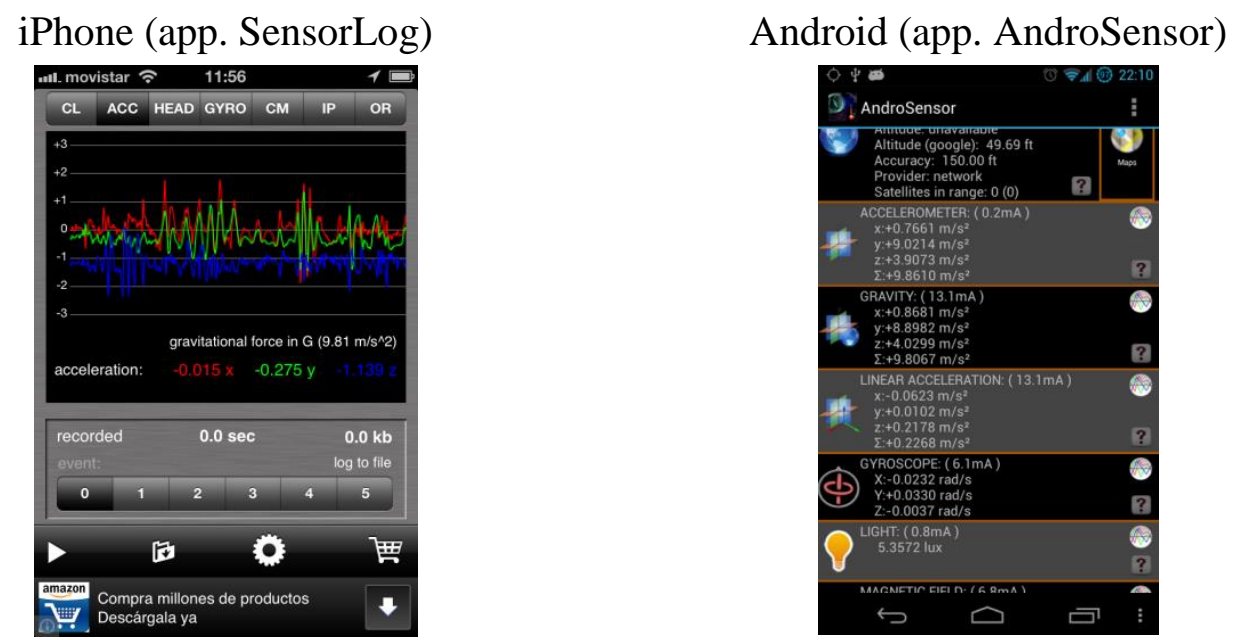

Fig. 2 - Smartphone's raw accelerometer and gyroscope measurements in different platforms

\subsection{Establishing the driving context}

The proposed methodology establishes the driving context (e.g. urban, freeway, congested, rural road driving, etc.) using only the smartphone measurements, without any additional parameter or source of information. This avoids the complexity of using external infrastructures' cartography and other sources of real time traffic information.

Two variables are used in order to establish the driving context: the average moving speed, " $\bar{V}$ ", (i.e. only considering speeds above a minimum speed threshold, " $V_{\min }$ ", below which the vehicle is considered to be stopped), and the portion of time stopped " $P$ ". Both variables are computed from raw GPS measurements with a frequency " $\tau$ ", and averaged over a time interval " $\Delta t$ ". In the pilot test on Section 3 these parameters take the values of " $\tau=0.1 \mathrm{~s}$ (10 $\mathrm{Hz}$ )", “ $\Delta t=5 \mathrm{~min}$, and " $V_{\min }=2 \mathrm{~km} / \mathrm{h} "$.

Finally, the " $\left(\bar{V}, P_{s}\right)$ " data points are grouped into homogeneous patterns using cluster analysis. Cluster analysis is a technique used to classify objects in homogeneous groups, called clusters (see [Anderberg, 1973] for a complete description of the cluster analysis method). Agglomerative hierarchical clustering is used here. The concept of the technique is simple. It consists in computing the "distance" between observations (i.e. the " $\left(\bar{V}, P_{s}\right)$ " vectors) and to bring together, at successive steps, those which are more similar (or "close"). The algorithm starts with as many groups as observations and finishes when all observations belong to only one group. The results do not provide a single partitioning, but only an optimal grouping process in a series of steps. The number of clusters does not need to be specified in advance (e.g. like it happens in the k-means clustering method). In order to obtain the final classification, it is necessary to cut the hierarchy of clusters at a given height. This allows including the preexisting knowledge, logic and experience in the results.

\subsection{Monitoring driving behavior: The tool and definition of the indicator}


Smartphones are equipped with an internal accelerometer. This provides measurements of the acceleration vector, in relation to the phone coordinate axis. From acceleration data, the jerk (i.e. the derivative of acceleration with respect to time, also called "surge") can be estimated. The jerk is a physics measurement considered to describe the aggressiveness in movement. Using the central differences method to compute the time derivative from discrete data points, the three components of the jerk vector (i.e. longitudinal, transversal and vertical jerks) with respect to the smartphone orientation, are obtained. However, the longitudinal and lateral jerks with respect to the direction of movement are the ones needed (see Figure 3). Therefore, the smartphone coordinate axis need to be reoriented with respect to the movement. One option could be to pre-orientate the smartphone in the vehicle, so that the coordinate axis of the smartphone and the vehicle coincide. This solution would invalidate the use of the app in motorcycles where the orientation of the vehicle is variable with the movement. In order to solve this, auto-calibration of the smartphone's coordinate axis is needed.

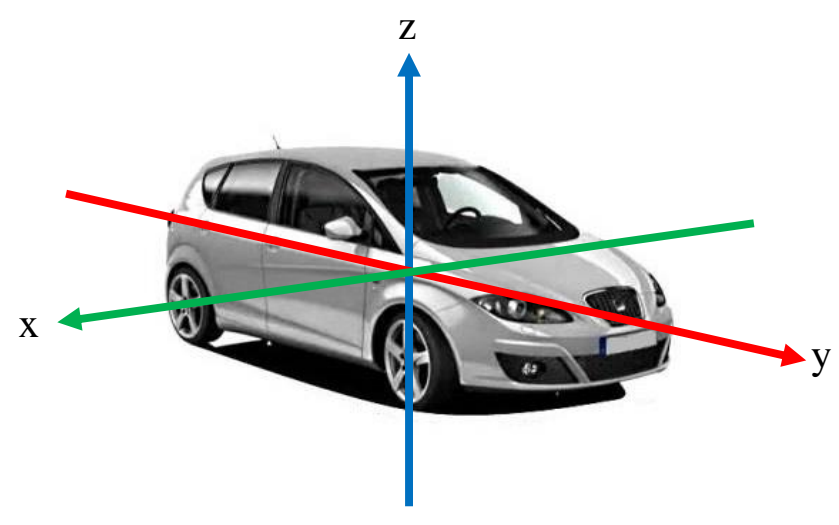

\section{Fig. 3 - Coordinate axis with respect to the direction of movement}

The experimental jerk data (presented in Section 3) reveal a useful property to achieve the auto-calibration. Jerk vectors are characterized by a primal variance direction. In other words, the hull of all jerk vectors is an ellipsoid of revolution (see Figure 4). A Principal Component Analysis (PCA) applied to the $(x, y, z)$ jerk vectors, determines that the direction of maximum variance always correspond to the direction perpendicular to the ground. This has been tested in many random positions of the smartphone, always with consistent results.

This property allows the reorientation of the jerk vector considering time intervals long enough to construct the ellipsoid of data. The selection of the time interval, " $\Delta t$ ", responds to a trade-off. On the one hand it should be long enough in order to accurately define the ellipsoid of revolution (at least 2-3 minutes). On the other hand, it should not extend to more than one driving context, and therefore needs to be short. " $\Delta t=5 \mathrm{~min}$ " has been selected, so that all samples include 3000 measurements (i.e. $5 \mathrm{~min}$ at $10 \mathrm{~Hz}$ ). This selection allows obtaining an ellipsoidal shape with precision and also to identify univocally a driving 
context.

The main drawback of the method is that the longitudinal direction " $x$ " cannot be differentiated from the transversal direction " $y$ ", and therefore "acceleration-braking" jerks cannot be isolated from "cornering" jerks. Only the " $x-y$ " plane, parallel to the ground, can be identified. In spite of this, the jerk projection on the " $x-y$ " plane is approximately circular (see Figure 4) implying similar magnitudes of these two jerk components. This means that the modulus of the jerk projection on the " $x-y$ " plane could be a good indicator of the driving aggressiveness.
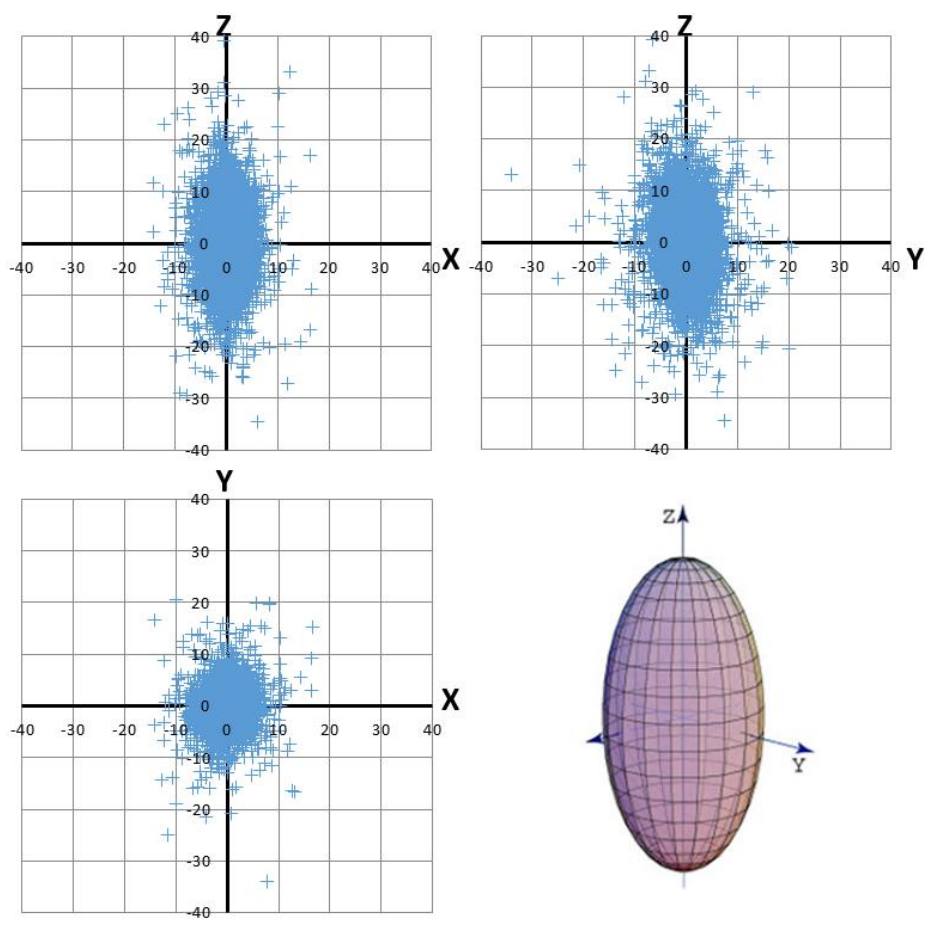

Fig. 4 - Jerk projections on coordinate planes in units of $\left[\mathrm{dm} / \mathrm{s}^{3}\right]$

Figure 5 shows the cumulative distribution function (cdf) of the jerk measurements of three driving samples. Note that, from now on, by "jerk measurement" it is meant the modulus of the jerk projections on the " $x-y$ " plane. These observations correspond to the same driver, travelling on the same route, but in a markedly calmed, medium-aggressive and aggressive driving. The three cdf's worthily distinguish each driving behavior. 


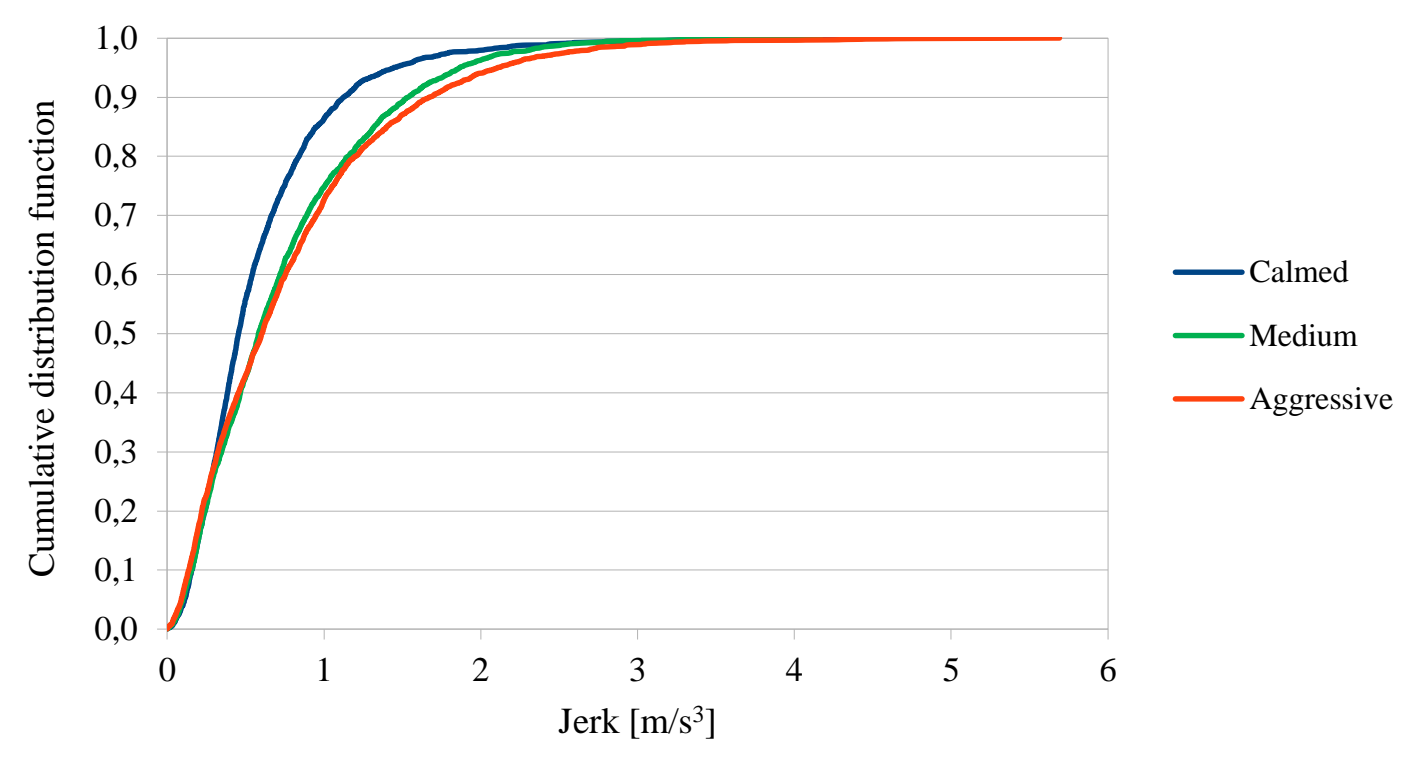

Fig. 5 - Cumulative distribution function (cdf) of the jerk measurements of three driving samples.

An indicator of aggressiveness (i.e. one value or a vector with different components) needs to be derived from the jerk's cdf. This selection should allow an easy identification of different aggressiveness patterns and clearly relate it to unsafe driving behavior. The mean jerk is an option. But probably, unsafe driving is more related to extreme jerks. Therefore, extreme value indicators, like the 99, 95, 90 or 85 percentiles, will probably perform better. The maximum jerk is discarded as an indicator because of its poor robustness, being largely affected by measurement errors.

\subsection{Relating aggressiveness with safe driving}

Safe driving behavior is established through surveying. The approach is based on the Driver Behavior Questionnaire (DBQ) [Parker et al., 1995], widely used in the study of driving psychology. Recent studies [Helman and Reed, 2015; Rowe et al. 2015] confirm the role of the DBQ survey as a valid measure of observed behavior in real driving and postulate that factors of the DBQ were significant independent predictors of crash involvement. The aim of this survey is to define a "theoretical classification of abnormal driving behaviors" [Zapf and Reason, 1994] through different types of factors. These include errors of action (i.e. the error in the translation between drivers' intention and their action), and errors of intention (i.e. the driver doing the wrong thing on purpose, either due to a mistake or due to a deliberate offense to traffic law). Errors and lapses have to do with the limited human capacity to treat and process huge amounts of data. Mistakes and violations relate to the experience and culture of the driver. 


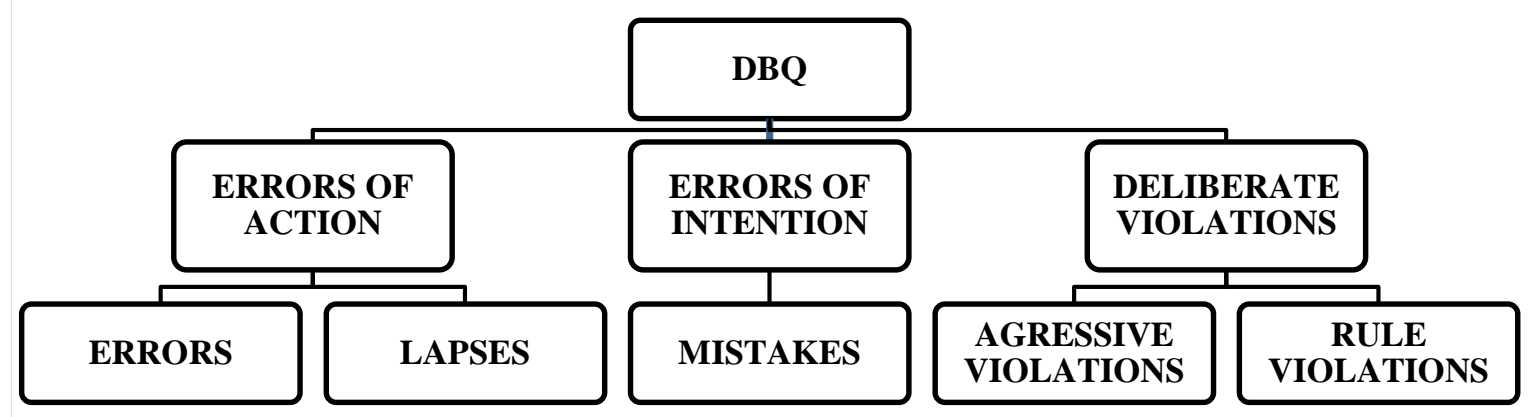

Fig. 6 - Driver Behavior Questionnaire (DBQ) surveying categories.

The most common version of the DBQ has been used in the present research, consisting of 28 questions (see Table 1). In addition, the surveying process has also provided other sampling information like the age, gender, experience and accidents/tickets rate of the driver, together with the characteristics of the vehicle.

From the DBQ responses, the DBQ index is computed. Factors are aggregated into two categories: i) errors of action, ii) errors of intention and deliberate violations. The DBQ index for each category is simply the mean of the grades (between 1 and 4) obtained in the questions that fall within the category. A global DBQ index is computed by averaging both partial indexes.

To establish the relationship between the DBQ indexes, obtained through the survey, and the indicator of the aggressiveness, obtained experimentally from the jerk measurements, multiple linear regression analysis is used. Results from this analysis provide a mathematical function that allows obtaining the DBQ index from the aggressiveness indicator. This derived DBQ index, suitably normalized between 0 and 10, will act as the safe driving grade that will provide feedback to the driver.

\section{PILOT TEST AND RESULTS}

\subsection{Experiment design}

In order to test and calibrate the methodology, a pilot test was performed. The experiment required two activities for each participant: i) record his driving activity with the drivers' feedback mobile app, and ii) answer the DBQ survey. Careful attention was paid to ensure that both the app and the survey were user-friendly. The pilot was limited to car and motorbike drivers. Iphone was selected as the smartphone platform for the pilot test. The uniformity in the iOS operating system simplified the SensorLog® app installation on all devices, and provided a uniform reliability of sensors. In contrast, this selection greatly limited the amount of potential participants. A user manual was created allowing the participants to set up the app independently. To help all participants to complete the survey, this was implemented in Google Forms®. Finally, all results where automatically received in ".csv" files ready to be processed. 


\begin{tabular}{|c|c|c|}
\hline \# & Factor & DBQ Questions \\
\hline 1 & Aggressive Viol. & $\begin{array}{l}\text { Become angered by another driver and give chase with the intention of giving } \\
\text { him/her a piece of your mind. }\end{array}$ \\
\hline 2 & Error & $\begin{array}{l}\text { Miss "Give Way" signs and narrowly avoid colliding with traffic having right of } \\
\text { way. }\end{array}$ \\
\hline 3 & Error & Fail to check your rear-view mirror before pulling out, changing lanes, etc. \\
\hline 4 & Aggressive Viol. & $\begin{array}{l}\text { Pull out of a junction so far that the driver with right of way has to stop and let } \\
\text { you out. }\end{array}$ \\
\hline 5 & Rule Viol. & $\begin{array}{l}\text { Drive back from a party, restaurant, or pub, even though you realize that you may } \\
\text { be over the legal blood-alcohol limit. }\end{array}$ \\
\hline 6 & Lapse & Misread the signs and exit from a roundabout on the wrong road. \\
\hline 7 & Rule Viol. & Disregard the speed limit on a residential road. \\
\hline 8 & Error & $\begin{array}{l}\text { Fail to notice that pedestrians are crossing when turning into a side street from a } \\
\text { main road. }\end{array}$ \\
\hline 9 & Lapse & $\begin{array}{l}\text { Intending to drive to destination A, you "wake up" to find yourself on the road to } \\
\text { destination B. }\end{array}$ \\
\hline 10 & Lapse & $\begin{array}{l}\text { Switch on one thing, such as the headlights, when you meant to switch on } \\
\text { something else, such as the wipers. }\end{array}$ \\
\hline 11 & Rule Viol. & Drive so close to the car in front that it would be difficult to stop in an emergency. \\
\hline 12 & Aggressive Viol. & $\begin{array}{l}\text { Stay in a motorway lane that you know will be closed ahead until the last minute } \\
\text { before forcing your way into the other lane. }\end{array}$ \\
\hline 13 & Lapse & Attempt to drive away from the traffic lights in third gear. \\
\hline 14 & Rule Viol. & Overtake a slow driver on the inside. \\
\hline 15 & Error & Attempt to overtake someone that you had not noticed to be signaling a right turn. \\
\hline 16 & Lapse & Forget where you left your car in a car park. \\
\hline 17 & Aggressive Viol. & Sound your horn to indicate your annoyance to another road user. \\
\hline 18 & Lapse & $\begin{array}{l}\text { Realize that you have no clear recollection of the road along which you have just } \\
\text { been travelling. }\end{array}$ \\
\hline 19 & Rule Viol. & Cross a junction knowing that the traffic lights have already turned against you. \\
\hline 20 & Error & On turning left nearly hit a cyclist who has come up on your inside. \\
\hline 21 & Error & $\begin{array}{l}\text { Queuing to turn left onto a main road, you pay such close attention to the main } \\
\text { stream of traffic that you nearly hit the car in front. }\end{array}$ \\
\hline 22 & Aggressive Viol. & $\begin{array}{l}\text { Become angered by a certain type of a driver and indicate your hostility by } \\
\text { whatever means you can. }\end{array}$ \\
\hline 23 & Error & Underestimate the speed of an oncoming vehicle when overtaking. \\
\hline 24 & Lapse & Hit something when reversing that you had not previously seen. \\
\hline 25 & Lapse & Get into the wrong lane approaching a roundabout or a junction. \\
\hline 26 & Aggressive Viol. & Get involved in unofficial races. \\
\hline 27 & Error & Brake too quickly on a slippery road or steer the wrong way in a skid. \\
\hline 28 & Rule Viol. & Disregard the speed limit on a motorway. \\
\hline
\end{tabular}

Table 1 - Driver Behavior Questionnaire

A total of 7 drivers participated in the pilot test ( 4 car and 3 motorcycle drivers). The majority were men (6/7). The age range was between 26 and 57 years old, being 35 the average. The average driving experience was 14 years, and their driving activity was related to both, commuting to work and leisure activities. Most of them have been involved in an accident in their driving life. 
The data collection lasted two months, between March and April 2015. A total of 88 complete and valid intervals of $5 \mathrm{~min}$. were recorded. Smartphones can record accelerometer measurements up to a frequency of $50 \mathrm{~Hz}$. However, frequencies higher than $10 \mathrm{~Hz}$ do not contribute in additional precision. Therefore, “ $\tau=0.1 \mathrm{~s}$ " was selected as the time interval between measurements. The valid measurements implied a total length of approximately 305 $\mathrm{km}$ with an average speed of $41.63 \mathrm{~km} / \mathrm{h}$.

\subsection{Driving contexts identification}

In order to establish the driving contexts, the previous sample size was extended including authors' own driving measurements, using both motorcycle and car. This allowed achieving 469 samples " $\left(\bar{V}, P_{s}\right)$ " averaged over 5 minutes. This means more than 39 hours of recording. Hierarchical clustering using the centroid method with Euclidean distance was applied on the IBM SPSS Statistics software. Figure 7 illustrates the clustering process. A grouping with 4 clusters was selected (see Table 2 and Figure 8). The decision of 4 clusters (instead of 3 which is also one possibility by looking at the dendrogram, see Figure $7 b$ ) is based on the knowledge of the Catalan infrastructures' classification, which differentiates between speed limits below or above $90 \mathrm{~km} / \mathrm{h}$. Table 3 summarizes the pilot test sample size in each driving context.

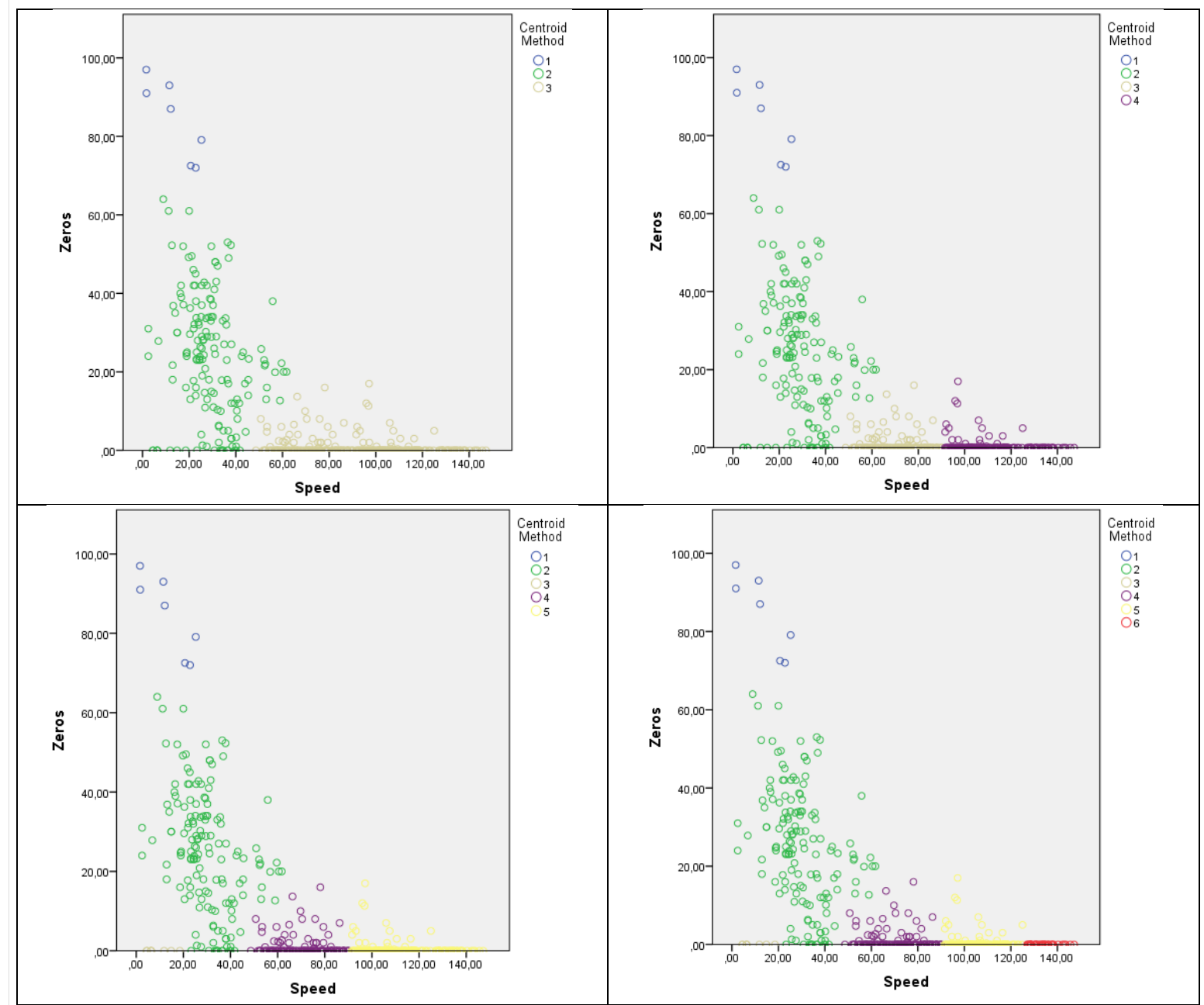

a) 


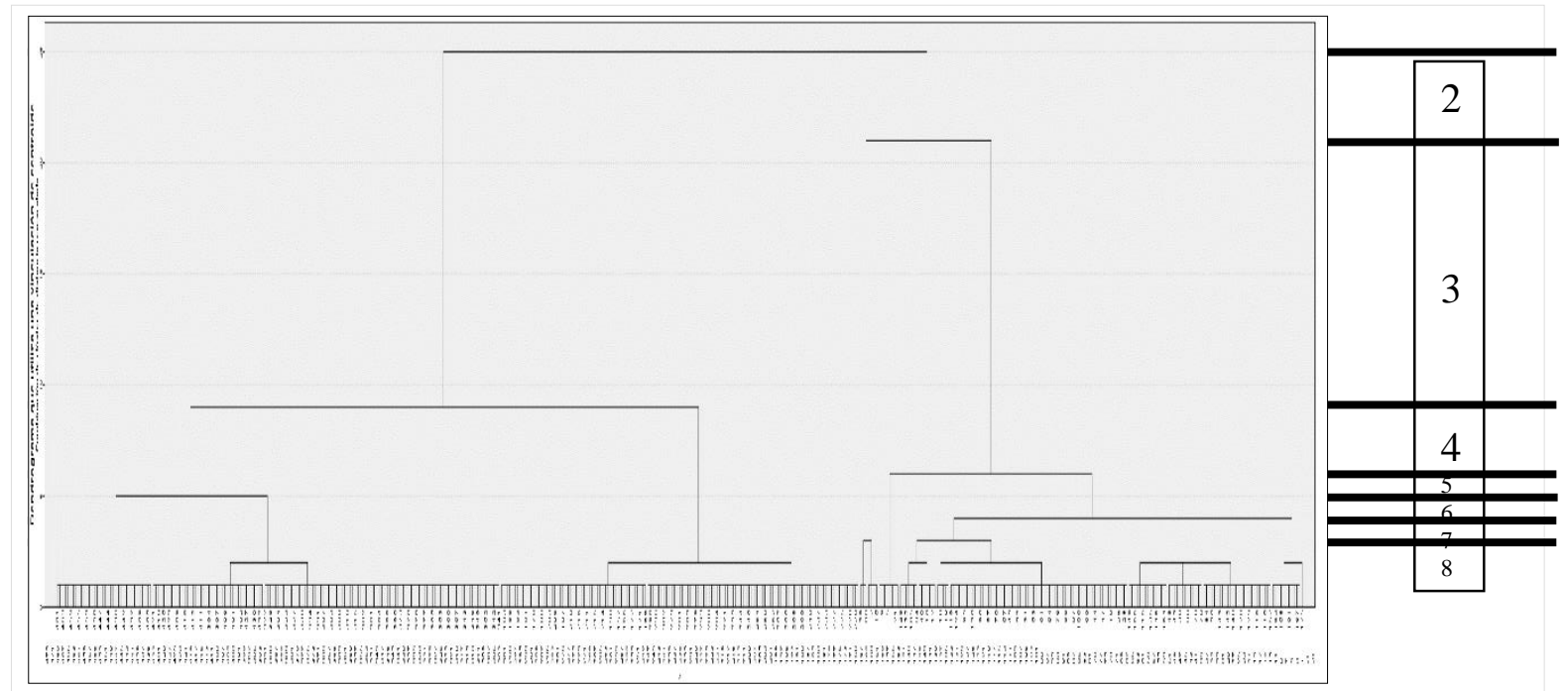

b)

Fig. 7 - Cluster analysis. a) Data belonging to 3, 4, 5 and 6 clusters. b) Dendrogram.

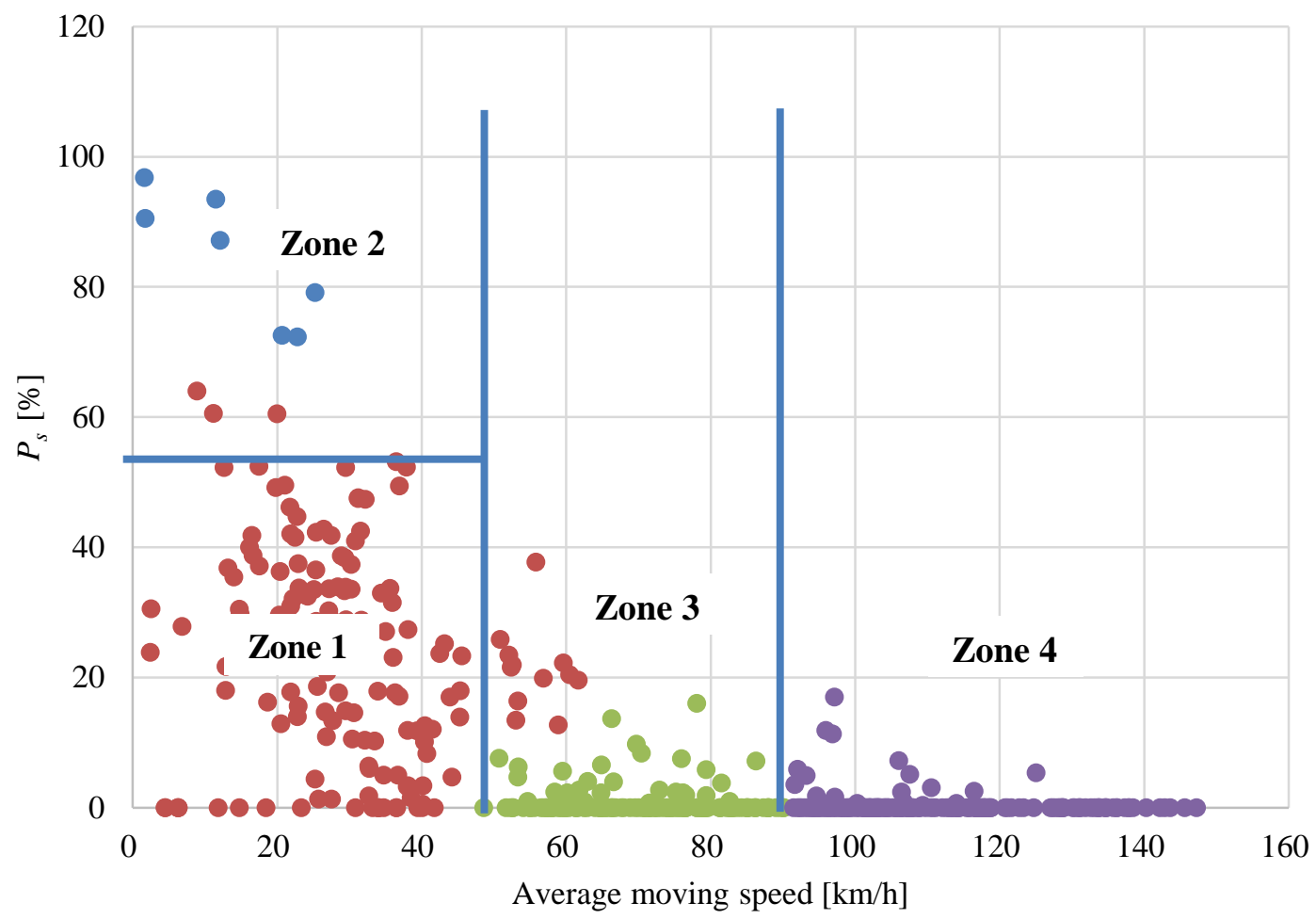

Fig. 8 - Driving context identification.

\begin{tabular}{|l|l|}
\hline Zone 1: $\bar{V}<50 \mathrm{~km} / \mathrm{h}, P_{s}<60 \% ;($ Urban) & $\begin{array}{l}\text { Zone 3: } 50 \mathrm{~km} / \mathrm{h}<\bar{V}<90 \mathrm{~km} / \mathrm{h} ; \\
\text { (Conventional roads / main arterials) }\end{array}$ \\
\hline Zone 2: $\bar{V}<50 \mathrm{~km} / \mathrm{h}, P_{s}>60 \% ;($ Congested) & Zone 4: $\bar{V}>90 \mathrm{~km} / \mathrm{h} ;$ (Freeway) \\
\hline
\end{tabular}

Table 2 - Boundaries of the different driving contexts 


\begin{tabular}{|c|c|c|c|c|c|}
\hline Car & $\mathbf{Z 1}$ & $\mathbf{Z 2}$ & $\mathbf{Z 3}$ & $\mathbf{Z 4}$ & Total \\
\hline D1 & 8 & & 4 & & 12 \\
\hline D2 & 5 & 1 & 6 & 3 & 15 \\
\hline D3 & 24 & 1 & 2 & & 27 \\
\hline D4 & 3 & & 8 & 2 & 13 \\
\hline Total & 40 & 2 & 20 & 5 & 67 \\
\hline
\end{tabular}

\begin{tabular}{|c|c|c|c|c|c|}
\hline Motorbike & $\mathbf{Z 1}$ & $\mathbf{Z 2}$ & $\mathbf{Z 3}$ & $\mathbf{Z 4}$ & Total \\
\hline D5 & 6 & & & & 6 \\
\hline D6 & 3 & & 6 & 4 & 13 \\
\hline D7 & 2 & & & & 2 \\
\hline Total & 11 & 0 & 6 & 4 & 21 \\
\hline
\end{tabular}

Table 3 - Pilot test sample size in each driving context for each driver

\subsection{Driving aggressiveness indicator and DBQ results}

Tables 4 and 5 summarize the Driving Aggressiveness Indicator, for car and motorbike drivers respectively. These are obtained from the cdf of the jerk measurements in each driving context. The DBQ results for each driver are also shown in the same tables. Cells are colored according to the magnitude of its value, in order to illustrate the existing correlation between the aggressiveness indicator and the DBQ results.

\subsection{Driver feedback grade}

With this extremely small sample size, little more than qualitatively suspecting the existence of correlation can be done. In spite of this, and only to illustrate the complete application of the methodology, linear regression analysis was performed in some of the contexts (see Table 6). Statistical robustness and significance of results are, of course, neglected. Despite these limitations, it was found that the best aggressiveness indicator is the $99^{\text {th }}$ percentile of the jerks' measurements, $" j_{99}$ th $"$. Therefore, the proposed regression model follows the form:

$$
D B Q=A+B \cdot j_{99}{ }^{t h}
$$

\begin{tabular}{|c|c|c|c|c|}
\hline Driving Context & Type of vehicle & A (intercept) & B (coefficient) & $\mathbf{R}^{\mathbf{2}}$ \\
\hline Zone 1 & Car & 0,995 & 0,134 & 0,80 \\
\hline Zone 3 & Car & 1,132 & 0,093 & 0,51 \\
\hline Zone 1 & Motorbike & 0,972 & 0,366 & 0,74 \\
\hline
\end{tabular}

Table 6 - Linear regression analysis

Finally, the model is applied to the pilot drivers and normalized to values between 0 and 10 , obtaining the feedback grades shown in Table 7.

\begin{tabular}{|c|c||c|c|}
\hline Car Driver & Grade & Motorbike Driver & Grade \\
\hline D1 & 9,1 & D5 & 7,1 \\
\hline D2 & 9,2 & D6 & 7,9 \\
\hline D3 & 8,9 & D7 & 9,1 \\
\hline D4 & 8,0 & & \\
\hline
\end{tabular}

Table 7 - Feedback grades in the pilot test 


\section{CAR}

\begin{tabular}{|l|ccccc|}
\hline Z1 & Jerk\%85 & Jerk\%90 & Jerk\%95 & Jerk\%99 & Mean \\
\hline D1 & 0,824 & 0,969 & 1,186 & 1,735 & 0,460 \\
D2 & 0,702 & 0,824 & 1,041 & 1,730 & 0,426 \\
D3 & 0,769 & 0,969 & 1,365 & 2,730 & 0,441 \\
D4 & 1,812 & 2,155 & 2,722 & 4,663 & 1,092 \\
\hline
\end{tabular}

\begin{tabular}{|cccc|cc|c|}
\hline Mistakes & Lapses & $\begin{array}{c}\text { Aggressive } \\
\text { Violation }\end{array}$ & $\begin{array}{c}\text { Rule } \\
\text { Violation }\end{array}$ & $\begin{array}{c}\text { Errors of } \\
\text { Action }\end{array}$ & $\begin{array}{c}\text { Deliberate } \\
\text { Violations }\end{array}$ & $\begin{array}{c}\text { DBQ } \\
\text { Index }\end{array}$ \\
\hline 1,13 & 1,25 & 1,00 & 1,33 & 1,19 & 1,17 & 1,18 \\
1,00 & 1,13 & 1,17 & 1,50 & 1,06 & 1,33 & 1,18 \\
1,67 & 1,33 & 1,00 & 2,00 & 1,50 & 1,50 & 1,50 \\
1,38 & 1,63 & 1,17 & 2,17 & 1,50 & 1,67 & 1,57 \\
\hline
\end{tabular}

\begin{tabular}{|l|ccccc|}
\hline Z2 & Jerk\%85 & Jerk\%90 & Jerk\%95 & Jerk\%99 & Mean \\
\hline D2 & 0,656 & 0,808 & 1,079 & 1,741 & 0,334 \\
D3 & 0,618 & 0,789 & 1,013 & 1,592 & 0,324 \\
\hline
\end{tabular}

\begin{tabular}{|cccc|cc|c|}
\hline Mistakes & Lapses & $\begin{array}{c}\text { Aggressive } \\
\text { Violation }\end{array}$ & $\begin{array}{c}\text { Rule } \\
\text { Violation }\end{array}$ & $\begin{array}{c}\text { Errors of } \\
\text { Action }\end{array}$ & $\begin{array}{c}\text { Deliberate } \\
\text { Violations }\end{array}$ & $\begin{array}{c}\text { DBQ } \\
\text { Index }\end{array}$ \\
\hline 1,00 & 1,13 & 1,17 & 1,50 & 1,06 & 1,33 & 1,18 \\
1,67 & 1,33 & 1,00 & 2,00 & 1,50 & 1,50 & 1,50 \\
\hline
\end{tabular}

\begin{tabular}{|l|ccccc|}
\hline Z3 & Jerk\%85 & Jerk\%90 & Jerk\%95 & Jerk\%99 & Mean \\
\hline D1 & 0,967 & 1,094 & 1,282 & 1,728 & 0,623 \\
D2 & 0,732 & 0,826 & 1,000 & 1,456 & 0,460 \\
D3 & 0,715 & 0,838 & 1,073 & 1,731 & 0,425 \\
D4 & 2,129 & 2,486 & 3,109 & 4,807 & 1,307 \\
\hline
\end{tabular}

\begin{tabular}{|cccc|cc|c|}
\hline Mistakes & Lapses & $\begin{array}{c}\text { Aggressive } \\
\text { Violation }\end{array}$ & $\begin{array}{c}\text { Rule } \\
\text { Violation }\end{array}$ & $\begin{array}{c}\text { Errors of } \\
\text { Action }\end{array}$ & $\begin{array}{c}\text { Deliberate } \\
\text { Violations }\end{array}$ & $\begin{array}{c}\text { DBQ } \\
\text { Index }\end{array}$ \\
\hline 1,13 & 1,25 & 1,00 & 1,33 & 1,19 & 1,17 & 1,18 \\
1,00 & 1,13 & 1,17 & 1,50 & 1,06 & 1,33 & 1,18 \\
1,67 & 1,33 & 1,00 & 2,00 & 1,50 & 1,50 & 1,50 \\
1,38 & 1,63 & 1,17 & 2,17 & 1,50 & 1,67 & 1,57 \\
\hline
\end{tabular}

\begin{tabular}{|l|ccccc|}
\hline Z4 & Jerk\%85 & Jerk\%90 & Jerk\%95 & Jerk\%99 & Mead \\
\hline D2 & 0,818 & 0,910 & 1,078 & 1,487 & 0,522 \\
D4 & 3,044 & 3,400 & 4,131 & 5,856 & 1,942 \\
\hline
\end{tabular}

\begin{tabular}{|cccc|cc|c|}
\hline Mistakes & Lapses & $\begin{array}{c}\text { Aggressive } \\
\text { Violation }\end{array}$ & $\begin{array}{c}\text { Rule } \\
\text { Violation }\end{array}$ & $\begin{array}{c}\text { Errors of } \\
\text { Action }\end{array}$ & $\begin{array}{c}\text { Deliberate } \\
\text { Violations }\end{array}$ & $\begin{array}{c}\text { DBQ } \\
\text { Index }\end{array}$ \\
\hline 1,00 & 1,13 & 1,17 & 1,50 & 1,06 & 1,33 & 1,18 \\
1,38 & 1,63 & 1,17 & 2,17 & 1,50 & 1,67 & 1,57 \\
\hline
\end{tabular}

Table 4 - Car drivers' pilot test measurements

This work is licensed under a Creative Commons Attribution-NonCommercial-NoDerivatives 4.0 International License (CC BY-NC-ND 4.0). 


\section{MOTORBIKE}

\begin{tabular}{|l|ccccc|}
\hline Z1 & Jerk\%85 & Jerk\%90 & Jerk\%95 & Jerk\%99 & Mean \\
\hline D5 & 0,850 & 1,053 & 1,441 & 2,464 & 0,462 \\
D6 & 0,626 & 0,766 & 1,046 & 1,764 & 0,368 \\
D7 & 0,152 & 0,222 & 0,350 & 0,783 & 0,090 \\
\hline
\end{tabular}

\begin{tabular}{|cccc|cc|c|}
\hline Mistakes & Lapses & $\begin{array}{c}\text { Aggressive } \\
\text { Violation }\end{array}$ & $\begin{array}{c}\text { Rule } \\
\text { Violation }\end{array}$ & $\begin{array}{c}\text { Errors of } \\
\text { Action }\end{array}$ & $\begin{array}{c}\text { Deliberate } \\
\text { Violations }\end{array}$ & $\begin{array}{c}\text { DBQ } \\
\text { Index }\end{array}$ \\
\hline 2,00 & 2,00 & 1,33 & 1,67 & 2,00 & 1,50 & 1,75 \\
1,33 & 1,33 & 2,67 & 2,00 & 1,33 & 2,33 & 1,83 \\
1,00 & 1,00 & 1,00 & 1,67 & 1,00 & 1,33 & 1,17 \\
\hline
\end{tabular}

\begin{tabular}{|l|crrrc|}
\hline Z3 & Jerk\%85 & Jerk\%90 & Jerk\%95 & Jerk\%99 & Mean \\
\hline D6 & 0,850 & 1,053 & 1,441 & 2,464 & 0,462 \\
\hline
\end{tabular}

\begin{tabular}{|cccc|cc|c|}
\hline Mistakes & Lapses & $\begin{array}{c}\text { Aggressive } \\
\text { Violation }\end{array}$ & $\begin{array}{c}\text { Rule } \\
\text { Violation }\end{array}$ & $\begin{array}{c}\text { Errors of } \\
\text { Action }\end{array}$ & $\begin{array}{c}\text { Deliberate } \\
\text { Violations }\end{array}$ & $\begin{array}{c}\text { DBQ } \\
\text { Index }\end{array}$ \\
\hline 1,33 & 1,33 & 2,67 & 2,00 & 1,33 & 2,33 & 1,83 \\
\hline
\end{tabular}

\begin{tabular}{|l|ccccc|}
\hline Z4 & Jerk\%85 & Jerk\%90 & Jerk\%95 & Jerk\%99 & Mean \\
\hline D6 & 0,684 & 0,772 & 0,933 & 1,315 & 0,435 \\
\hline
\end{tabular}

\begin{tabular}{|cccc|cc|c|}
\hline Mistakes & Lapses & $\begin{array}{c}\text { Aggressive } \\
\text { Violation }\end{array}$ & $\begin{array}{c}\text { Rule } \\
\text { Violation }\end{array}$ & $\begin{array}{c}\text { Errors of } \\
\text { Action }\end{array}$ & $\begin{array}{c}\text { Deliberate } \\
\text { Violations }\end{array}$ & $\begin{array}{c}\text { DBQ } \\
\text { Index }\end{array}$ \\
\hline 1,33 & 1,33 & 2,67 & 2,00 & 1,33 & 2,33 & 1,83 \\
\hline
\end{tabular}

Table 5 - Motorbike drivers' pilot test measurements 


\section{CONCLUSIONS}

One of the main problems regarding driving performance is the lack of feedback to the driver. This paper addresses the methodology behind a smartphone app that provides feedback to the driver in terms of a safe driving grade. The methodology is generic and can be used in any smartphone platform, provided that accelerometer and GPS measurements are available. No other source of information is needed. Aggressive and risky driving behavior is established by computing the jerk cumulative distribution function (cdf). This is related to safe driving by regression analysis with respect to the results of the DBQ (i.e. the Driving Behavior Questionnaire). A pilot test of the methodology allowed identifying four different driving contexts (i.e. urban, congested, conventional road/main arterial and freeway), and calibrating the correlation between the $99^{\text {th }}$ percentile of the jerks' cdf and the DBQ results in some of them. The small sample size of the pilot test, with only 7 drivers, prevents any kind of statistical significance of the data presented herein. The feedback grades for the 7 drivers are only obtained for illustrative purposes.

The presented method needs to be refined. Further research will include looking for solutions that eliminate the need of using GPS data. This would reduce significantly the smartphones' battery consumption. An extensive pilot test would be necessary to establish robust correlation models between the jerks' cdf and the DBQ results. Finally, a method for normalizing the obtained grades, accounting for possible bias in the answers to the survey needs also to be investigated.

The ultimate objective of the driver feedback app is to ease the drivers' learning and selfassessment, so that they can gradually improve their performance and monitor the evolution. This will have an effect on the human factor in driving, the main cause of traffic accidents, avoiding near accident situations and finally, reducing accident rates. Other applications and sub products are also possible. These might include the establishment of detailed causeeffect relationships between aggressive driving and the associated risk, valuable information in order to improve road safety as well as for insurance companies, applications for vehicle fleet management, geolocation of dangerous spots in a road network or as a tool for objective proving driving behavior, in order to qualify for premiums in vehicle insurances or for being retrieved the driving license after a revocation.

\section{ACKNOWLEDGEMENTS}

The author acknowledges the collaboration of JuanPe Roldán and Bernat Garcia for their work on the preliminary data analysis and mathematical contributions, and to Cesar Trapote, for his knowledge and help with the DBQ survey. Thanks also to the 7 drivers who unselfishly participated in the pilot test. Without their contribution this research would not have been possible. This research has been partially funded by the Spanish Ministry of Economy and Competitiveness (TRA2013-45250-R/CARRIL) and partially supported by a 
grant from Iceland, Liechtenstein and Norway through the EEA Financial Mechanism. Operated by Universidad Complutense de Madrid.

\section{REFERENCES}

- ANDERBERG, M. R. (1973). Cluster Analysis for applications. Academic Press, New York.

- 2BESAFE. (2011). Two wheeler behavior and safety. European Commission. Belgium. http://www.2besafe.eu.

- CARE. (2011). European road accident database. European Commission.

- CHESHAM, D.J., D.R. RUTTER and L. QUINE. (1993). Motorcycling safety research: a review of the social and behavioral literature. Social Science and Medicine 37(3), 419-429.

- EMS INSIDER. (2004). Vehicle monitoring systems, please providers and patients. EMS Insider, August 2004, 7.

- HELMAN, S. and N. REED. (2015). Validation of the Driver Behaviour Questionnaire Using Behavioural Data from an Instrumented Vehicle and High-Fidelity Driving Simulator. Accident Analysis \& Prevention 75, 245-51.

- MANUELE, F. (2003). On the practice of safety. Wiley Interscience, New York.

- NHTSA. (2007). Unconscious motivators and situational safety belt use. Traffic Safety Facts: Traffic Tech. 315. National Highway Traffic Safety Administration. Washington D.C.

- PARKER, D., J.T. REASON, A.S.R. MANSTEAD, and S.G. STRADLING. (1995). Driving Errors, Driving Violations and Accident Involvement. Ergonomics 38(5), 1036-48.

- $\quad$ ROWE, R., G.D. ROMAN, F.P. MCKENNA, E. BARKER, and D. POULTER. (2015). Measuring Errors and Violations on the Road: A Bifactor Modeling Approach to the Driver Behavior Questionnaire. Accident Analysis \& Prevention 74, 118-25.

- SCT. (2014). 2014 Statistical yearbook of traffic accidents in Catalonia. Servei Català del Trànsit.

- SHRP2. (2007). A foundation for safer driving. Proceedings of the Transportation Research Board, April 2007, Washington D.C.

- VANDERBILT, T. (2009). Traffic: Why we Drive the way we do (and what it says about us). Penguin Books Ltd, United Kingdom.

- WALTON, D. and J. BATHURST. (1998). An exploration of the perceptions of average driver's speed compared with perceived driver safety and driving skill. Accident Analysis and Prevention 30, 821-830.

- ZAPF, D. and J.T. REASON. (1994). Introduction- Human Errors and Error Handling. Applied psychology - An international review - Psychologie appliquee - Revue Internationale 43(4), 427-32. 